\title{
NUMERICAL ANALYSIS OF RECTANGULAR GROOVE CUTTING WITH DIFFERENT RC TOOLS
}

\author{
Deng, W. J.; Li, Q.; Xie, Z. C. \& Lin, P. \\ School of Mechanical and Automotive Engineering, South China University of Technology, \\ Guangzhou 510641, China \\ E-Mail: dengwj@scut.edu.cn
}

\begin{abstract}
The paper reports an advanced finite element analysis code for the investigation of the cutting process of rectangular groove. Three different restricted contact tools (RC tools) with rectangular, trapezoidal and double-trapezoidal shapes were employed in this study. The cutting force, feed force and rake face temperature distribution during the cutting process were analysed. The simulation results show that asymmetric tool-chip restricted contact shape causes the chip to break more easily than the symmetric tools. The RC tool shows significant reductions both in cutting force $(6 \sim 8 \%)$ and feed force $(70 \sim 80 \%)$ than traditional tools. It is also found that the $\mathrm{RC}$ tools give $12 \%$ reduction in mean temperature on tool rake face compared to those of traditional tools. The simulation results indicate that the tools with asymmetric tool-chip contact shapes have advantages over symmetrical ones in terms of decreasing chip breakage, reducing cutting force and tool cooling.

(Received in September 2012, accepted in December 2012. This paper was with the authors 1 month for 1 revision.)
\end{abstract}

Key Words: Restricted Contact Shape, RC Tools, FEM, Rectangular Groove Cutting, Metal Cutting

\section{INTRODUCTION}

High cutting speeds made possible with modern cutting machines, and inconvenient chip forms that result from machining materials such as steel, necessitate development of new tool designs. Restricted contact tools have shown several advantages in machining processes and considerable research has been carried out in the area. Klopstock [1] introduced restricted contact tools (RC tools) and showed 15 25\% reduction in cutting forces, a decrease of $100{ }^{\circ} \mathrm{C}$ in chip temperature and prolonged tool life. De Chiffre [2] optimized the use of RC tools through experiments which showed that the amount of extreme-pressure additives in cutting fluids can be reduced by using RC tools. Sadik and Lindström [3] studied the relationship between tool-chip contact length, tool life and tool temperature. Their experiments showed that reducing tool-chip contact length within a certain value could decrease flank wear. Huang et al. [4] found that the cutting force and tool temperature reduced when the tool-chip contact length was restricted to a certain value.

Arsecularatne [5] adopted a semi-empirical method based on Oxley's machining theory to predict RC tool life. His study showed that a decrease in restricted contact length to a certain limit increased the tool life but further decrease in contact length caused a decrease in tool life. Jawahir et al. performed extensive researches on RC tools. In 1999, they proposed a universal slip-line model that contains six major slip-line models previously developed for two-dimensional machining. Their research accounted for the phenomena of chip curl and chip back-flow when machining with RC tools. As shown in Fig. 1 [6], the whole slip-line field is composed of five regions: (a) a region BFG adjacent to the tool rake face which 
accounts for the specific friction condition between the underside of the deformed chip and the tool rake face; (b) a curvilinear triangular region EFG directly providing the chip back-flow effect; (c) A curvilinear triangular region BDF resulting from the stress singularity at point $\mathrm{B}$ at the tip of the tool; (d) a convex shear plane $\mathrm{AC}$ directly providing the chip up-curling effect; (e) a curvilinear quadrilateral region CDFE connecting the shear plane AC and the two regions EFG and BDG. Following this, analytical predictions and experimental validations of the universal slip-line model were presented [7]. There was reasonable agreement between theoretical and experimental results. Based on the universal slip-line model, Jawahir et al. developed new analytical models to predict chip back-flow angle [8], tool-chip interface friction and chip-groove effects [9] in machining with RC tools.

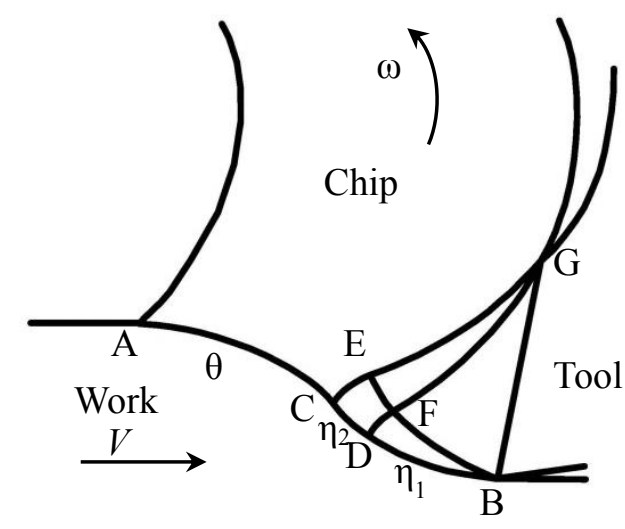

Figure 1: Schematic diagram of universal slip-line field model.

In recent years, the Finite Element Method (FEM) has been gaining importance as a tool to predict cutting performance [10-17]. FEM has been used to investigate effects of friction in cutting, shear stress on the chip-tool interface, burr formation, temperature distribution on cutting zone etc. Arrazola et al. [10] used FEM to understand the effects of the friction model on the chip formation process, cutting force and temperature. Based on a FE model, Zhang et al. [11] studied the limit shear stress on tool-chip interface during dry cutting of titanium alloy. They suggested a relationship between surface limiting shear stress and the coefficient of fiction, which agreed well with experimental data from literature. Grzesik et al. [12] used a commercial finite element code to study the temperature distribution on the cutting zone in turning process with differently coated tools. Good agreement between predicted and experimental cutting temperature was reported, especially for uncoated and three-layer coated tools. Tamizharasan and Senthil Kumar [13] used Taguchi's Design of experiment [14] to design experiments for minimizing flank wear of uncoated carbide inserts. A validation finite element simulation which showed satisfactory results was conducted with obtained optimum tool geometry. In Niţu's research [15], a FE simulation of the cold rolling process by using an optimized FE mesh and the stress-strain law is performed. The results show that valuable information could be obtained from FE simulations. In our previous study [16], by using commercial finite element code (Deform), the profile of the predicted burr which formed near the exit of orthogonal cutting was found to agree reasonably well with experimental result.

However, most of the earlier studies on RC tools have only focused on the rectangular tool-chip contact. In actual cutting processes, the shape of the tool-chip contact may be irregular, which may lead to uneven temperature distribution, reduction in resultant force, complicated chip curling and may ultimately affect integrity of the workpiece and tool wear. This paper reports FEM studies on the effect of tool-chip contact shapes of RC tools on cutting performance. 


\section{FINITE ELEMENT MODELING OF RECTANGULAR GROOVE CUTTING}

A commercial finite element code (Deform-3D) was used for three-dimensional thermo-mechanical Finite Element Modeling of the rectangular groove cutting process in this study. The rectangular groove cutting model is based on an orthogonal cutting method. In this analysis, an unsymmetrical tool-chip restricted contact shape of cutting tool is used. For convenient comparison with other cutting tools, a uniform model is adopted. Since the bar-shaped workpiece has a larger diameter compared to the section of workpiece using in the finite element analysis model, the workpiece in this model can be simplified as a cuboid, as shown in Fig. 2a. The cuboid is $10 \mathrm{~mm}$ in length, $6 \mathrm{~mm}$ in width and $2 \mathrm{~mm}$ in height. The cutting tool is shown in Fig. 2a with its tool edge $3 \mathrm{~mm}$ in length. It is placed below the top surface $A B C D$ of the workpiece in advance. The distance between tool edge and the top surface $A B C D$ of workpiece equals the value of feed rate used in the cutting process. Faces EFGH, BCGF, CGHD and ABFE are constrained in all directions and the tool is set to move in a specific direction with an assigned cutting speed.

Tetrahedral elements are used to model the tool and workpiece. Fig. $2 b$ shows the initial finite element mesh. About 50,000 elements are obtained by the tool model and double the number of elements are used to model the workpiece. For the purpose of predicting the deformation field and chip geometry accurately, a finer mesh is maintained in the regions of deformation zone by defining a high mesh density window $W$ which covers the tool-chip contact area and moves with the tool. The element sizes near the cutting edge of the tool and the deformation zone of the workpiece are $0.07 \mathrm{~mm}$ and $0.06 \mathrm{~mm}$, respectively.

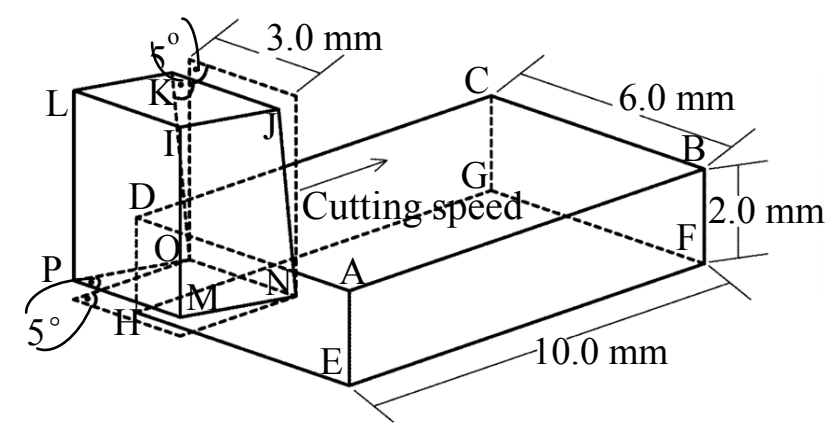

a)

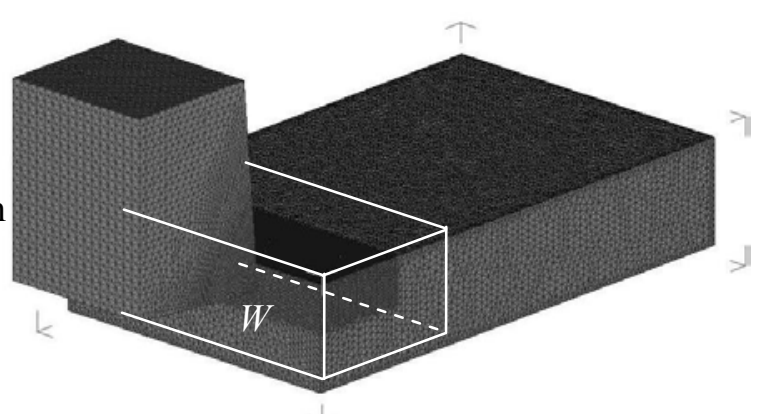

b)

Figure 2: The geometry and mesh of rectangular groove cutting model: a) 3D; b) mesh-3D.

Three types of tool with different restricted contact shapes on the rake face are shown in Fig. 3. The shapes include rectangular, trapezoidal and double-trapezoidal, each with their designed geometry dimensions shown. In addition, the shape areas of the three tools are equal to $0.15 \mathrm{~mm}^{2}$.

The workpiece material used for simulation is medium steel AISI1045 with a Poisson's ratio of 0.3 . The workpiece is modelled as a deformable body with rigid-plastic material data which is dependent on strain, strain rate and temperature. The flow stress is a function of strain, strain rate and temperature [18-20]:

$$
\sigma=f(\varepsilon, \dot{\varepsilon}, T)
$$

where $\sigma$ is the flow stress, $\varepsilon$ the plastic strain, $\dot{\varepsilon}$ the plastic strain rate, and $T$ the workpiece temperature. 


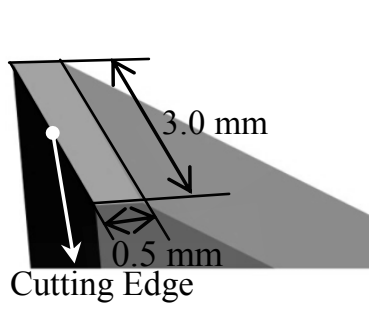

a)

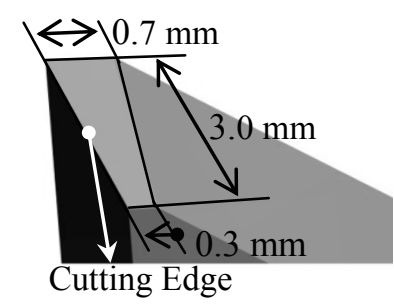

b)

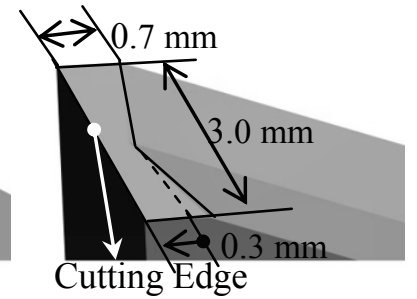

c)

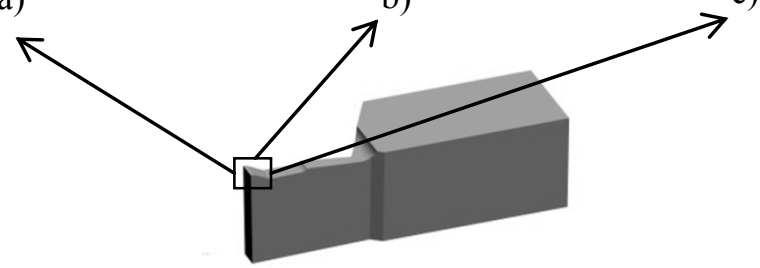

Figure 3: Three tools with different restricted contact shapes: a) Rectangular; b) Trapezoidal; c) Double-trapezoidal.

During the cutting process, the workpiece material at the cutting zone undergoes severe plastic deformation with high strain, high strain rate and elevated temperature. In the finite element analysis, flow stress is tabulated for different strain rates and temperatures. The flow stress curve can be captured by these data. Fig. 4 shows samples of the flow stress curve at 20 ${ }^{\circ} \mathrm{C}$ and $300{ }^{\circ} \mathrm{C}$ when strain rate is $10^{1}, 10^{3}$ and $10^{5}$. Stress under other temperature and strain rate can be obtained by interpolation and extrapolation. The other properties of the workpiece material including modulus of elasticity, thermal expansion, thermal conductivity and heat capacity are all dependent on the temperature as shown in Table I. The cutting tool is perfectly sharp and modelled as a rigid but heat transfer body. Its material is defined as tungsten carbide with the following properties:

a. Density: $12700 \mathrm{~kg} / \mathrm{m}^{3}$

b. Thermal conductivity: $59 \mathrm{~W} / \mathrm{m}^{\circ} \mathrm{C}$

c. Heat capacity: $15 \mathrm{~J} / \mathrm{K}$

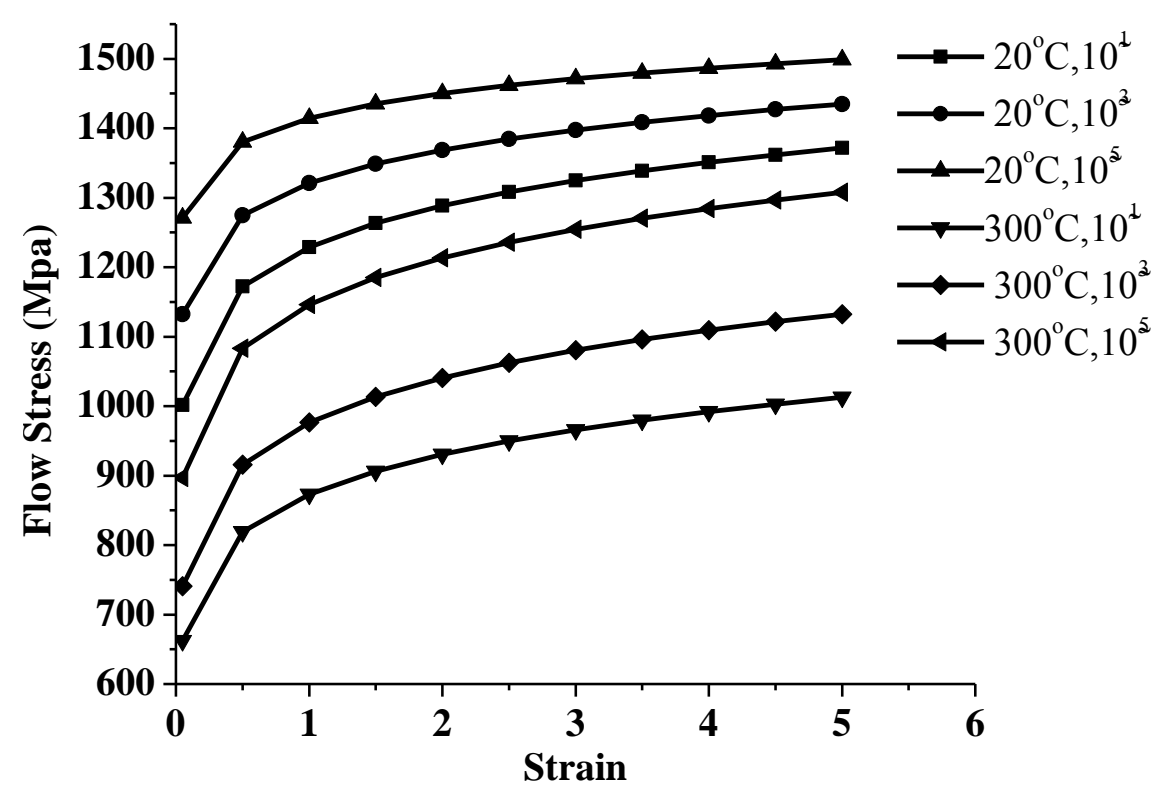

Figure 4: Flow stress-strain curve of the workpiece material. 
Table I: Temperature-dependent physical properties of the workpiece.

\begin{tabular}{|c|c|c|c|c|}
\hline $\begin{array}{c}\text { Temperature } \\
\left({ }^{\circ} \mathrm{C}\right)\end{array}$ & $\begin{array}{c}\text { Modulus of } \\
\text { Elasticity } \\
(\mathrm{GPa})\end{array}$ & $\begin{array}{c}\text { Thermal } \\
\text { Expansion } \\
\left(\times 10^{-5}\right)\end{array}$ & $\begin{array}{c}\text { Thermal } \\
\text { Conductivity } \\
\left(\mathrm{W} / \mathrm{m}^{\circ} \mathrm{C}\right)\end{array}$ & $\begin{array}{c}\text { Heat } \\
\text { Capacity } \\
\left(\mathrm{J} /{ }^{\circ} \mathrm{C}\right)\end{array}$ \\
\hline 20 & 212 & 1.19 & 41.7 & 3.61 \\
\hline 100 & 207 & 1.25 & 43.4 & 3.89 \\
\hline 200 & 199 & 1.30 & 43.2 & 4.18 \\
\hline 300 & 192 & 1.36 & 41.4 & 4.45 \\
\hline 400 & 184 & 1.41 & 39.1 & 4.80 \\
\hline 500 & 175 & 1.45 & 36.7 & 5.31 \\
\hline 600 & 164 & 1.49 & 34.1 & 6.12 \\
\hline
\end{tabular}

The heat sources responsible for large temperature rise during rectangular groove cutting include: (a) heat generation due to plastic deformation of the workpiece (mechanical energy) in the primary and secondary deformation zone; (b) friction-generated heat at the tool-chip and tool-workpiece interface.

In this analysis, the heat transfer in the simulation model is based on the following assumption: (a) The main sources of heat during metal cutting are the plastic deformation work and the friction at the tool-workpiece interface. In this study, $95 \%$ of the plastic deformation and $100 \%$ of the friction work are assumed to be converted into heat; (b) The tool-chip contact is thermally perfect, i.e., a very large value for the interface heat transfer coefficient is used; (c) The surfaces EFGH, BCGF of the workpiece and the surfaces IJKL, MILP of the tool are far from the cutting zone and remain at the room temperature $20{ }^{\circ} \mathrm{C}$; in other free surfaces of workpiece, chip, and tool, heat loss due to convection is considered; (d) Heat transfer by radiation is considered insignificant and negligible. Therefore, it is not taken into account.

In the machining process, the sticking region and the sliding region exist simultaneously on the tool rake face [21-23]. In the sticking region the critical shear stress is assumed to be equal to the friction stress, while the classic Coulomb friction law is applied in the sliding region. According to the Coulomb friction law, the friction force is given as:

$$
f=\mu \sigma_{n}
$$

where $f$ is the friction stress, $\mu$ the frictional coefficient, $\sigma_{n}$ the normal stress along the tool rake face. The friction coefficient is assumed to be 0.5 in this analysis.

\section{RESULTS AND DISCUSSION}

\subsection{Formation and morphology of a chip}

Early finite element models which applied chip separation criterion may lead to limitations during the chip formation. The parameters used in the chip separation criterion are difficult to determine and the chip geometry changes with different parameters adopted. In this research, an auto remeshing technique is adopted to circumvent this problem. The remeshing procedure is automatically activated whenever the element has very high distortion or the tool penetration exceeds a critical value which is set default to two times of the tool-chip contact tolerance value in this analysis. Then, a new boundary between the tool and the workpiece in the tool-workpiece interface is generated. The check of tool penetration or element distortion 
is performed at each iteration and the end of time increments so that the accuracy of chip formation is ensured. As the accuracy of the simulation improves with a decrease in the time step length, here in this simulation, the time step length is as small as $1.27 \times 10^{-5}$ second.

Table II shows the process of chip formation with four kinds of tools. The cutting speed is $94.2 \mathrm{~m} / \mathrm{min}$ and the undeformed chip thickness $0.5 \mathrm{~mm}$. At the very beginning $(t=0 \mathrm{~ms})$, there is no interaction between the tool and the workpiece. When the unrestricted contact tool moves forward ( $t=0.045 \mathrm{~ms})$, as shown in the second column of Table II, an indentation occurs at the tool-workpiece interface. Severe deformation of the workpiece around the tool edge is generated due to the large effective stress in the following process. Part of the material in the cutting zone flows along the rake face and forms the chip. As the tool continually moves, a steady symmetrical rectangular tool-chip contact area appears. The width of this rectangle is called tool-chip contact length [1-5]. According to the precious experimental study [1,2], there is a relationship between the contact length factor $n=L / t$ and the chip compression factor $\lambda=t / t^{\prime}$ :

$$
\lambda=\sqrt{1+n \cos \alpha}
$$

where $L$ is the tool-chip contact length, $t$ uncut chip thickness, $t^{\prime}$ chip thickness, $\alpha$ rake angle.

From the data in Table III, it can be seen that the simulated value of the tool-chip contact length agrees well with the eq. (3). The chip compression factor error between the result from simulation and the result from calculation of eq. (3) is only $0.7 \%$.

The shapes of chips are similar on using the rectangular and the double-trapezoidal shapes $\mathrm{RC}$ tools respectively, as shown in the third and the fifth columns in Table II. However, asymmetric chip geometry is obtained (the fourth column of Table II) on using the tool with trapezoidal restricted contact shape. The chip rolls to one side and deviates from the cutting direction, which makes the chip easier to break as it interacts with workpiece surface. Furthermore, side curling of the chip can avoid scratchesing the machined surface of the workpiece, which is very important in precision machining.

Table II: The process of chip formation with different cutting tools.

\begin{tabular}{|c|c|c|c|c|}
\hline $\begin{array}{c}\text { Tool } \\
\text { Displacement } \\
(\mathrm{mm})\end{array}$ & Traditional & Retangular & Trapezoidal & $\begin{array}{c}\text { Double- } \\
\text { trapezoidal }\end{array}$ \\
\hline 0.1 & & & & \\
\hline 2.8 & & & & \\
\hline 5
\end{tabular}


Table III: Simulated result of tool-chip contact length.

\begin{tabular}{|l|c|}
\hline Tool-chip contact length $L(\mathrm{~mm})$ & 0.705 \\
\hline Uncut chip thickness $t(\mathrm{~mm})$ & 0.500 \\
\hline Chip thickness $t^{\prime}(\mathrm{mm})$ & 0.781 \\
\hline Rake angle $\alpha\left(^{\circ}\right)$ & 5 \\
\hline chip compression factor $\lambda$ & 1.562 \\
\hline$\sqrt{1+n \cos \alpha}$ & 1.551 \\
\hline
\end{tabular}

The morphologies of chips produced using different kinds of tools are shown in Fig. 5. The simulation results show that the mean chip up-curl diameter [7] is obviously influenced by the shape of the tool-chip contact geometry. The mean chip up-curl diameter is $1.69 \mathrm{~mm}$ using traditional cutting tool. It is $2.22 \mathrm{~mm}, 2.06 \mathrm{~mm}$ and $1.86 \mathrm{~mm}$ for trapezoidal, rectangular and double-trapezoidal $\mathrm{RC}$ tool, respectively. It demonstrates that the obstruction effect of tool-chip contact on the chip flow decreases while the tool-chip contact length is reduced. Then the chip flows more freely, which results in the formation of a large diameter of chip curling. The advent of automatic machining process requires strict control of the chip morphology. To some extent, asymmetric contact zone is an alternative method to control chip breakage.

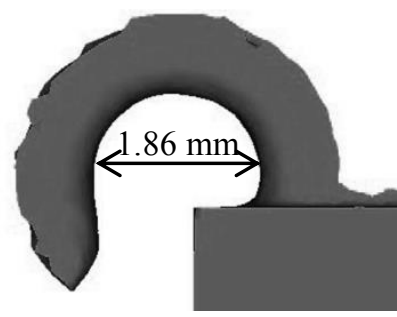

a)

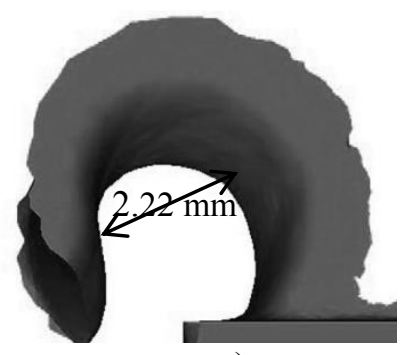

c)

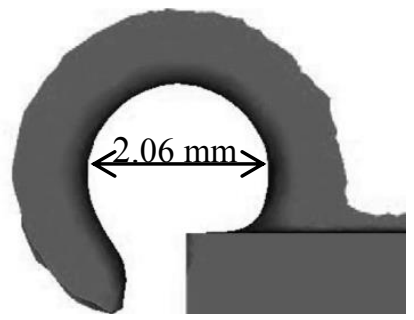

b)

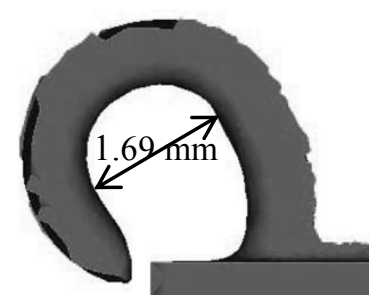

d)

Figure 5: Morphologies of chips: a) Traditional; b) Rectangular; c)Trapezoidal; d) Doubletrapezoidal.

\subsection{Force comparison}

The simulated cutting force and feed force in the rectangular groove machining process are shown in Fig. 6. It can be observed that a steady state is reached very quickly after the initiation of the cutting process at about $0.5 \mathrm{~ms}$ for the traditional tool and about $0.2 \mathrm{~ms}$ for the other three tool-chip RC tools. At steady state, the cutting force reaches a value of about $3354 \mathrm{~N}$ for traditional tool and $3145 \mathrm{~N}, 3130 \mathrm{~N}$ and $3097 \mathrm{~N}$ for the tool-chip restricted contact tools with rectangular, trapezoidal, and double-trapezoidal contact surfaces respectively. By applying the tool-chip restricted contact tools, an $8 \%$ decrease in cutting force is obtained 
compared to the traditional tools. In addition, the result also shows that the mean feed force is about $170 \mathrm{~N}$ for traditional tool and about $39 \mathrm{~N}, 33 \mathrm{~N}$ and $50 \mathrm{~N}$ for tools with rectangular, trapezoidal and double-trapezoidal restricted contact surfaces, respectively. Compared to the traditional tools, tool-chip RC tools could decrease the feed force by about $80 \%$ which means energy consumption during cutting process is reduced.

\subsection{Temperature analysis}

The finite element method is being increasingly used as an effective route to predicting temperature distribution due to difficulties in measuring temperature of the cutting zone and tool rake face in experiments [12], [24-27]. The plastic deformation and friction at the tool-chip interface are the main source of heat during the cutting process. The cutting zone temperature gradually increases as the tool moves forward. However, the mean change rate of the highest temperature in the cutting zone decrease from $2.21{ }^{\circ} \mathrm{C}$ per step to $0.032{ }^{\circ} \mathrm{C}$ per step when the tool moves $8.2 \mathrm{~mm}$ forward, which means that the cutting process comes to a steady state.

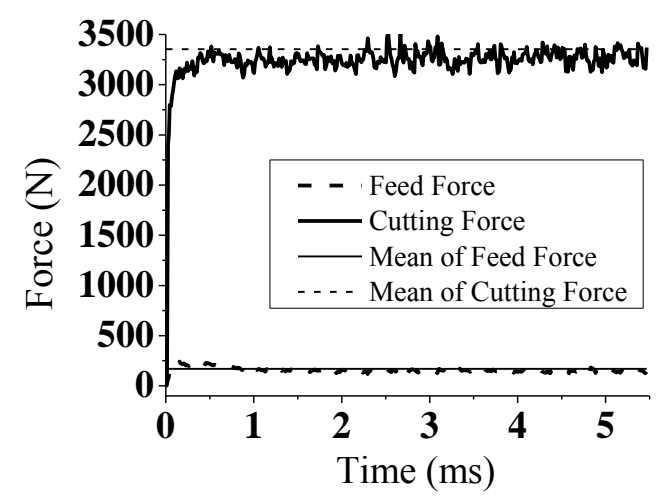

a)

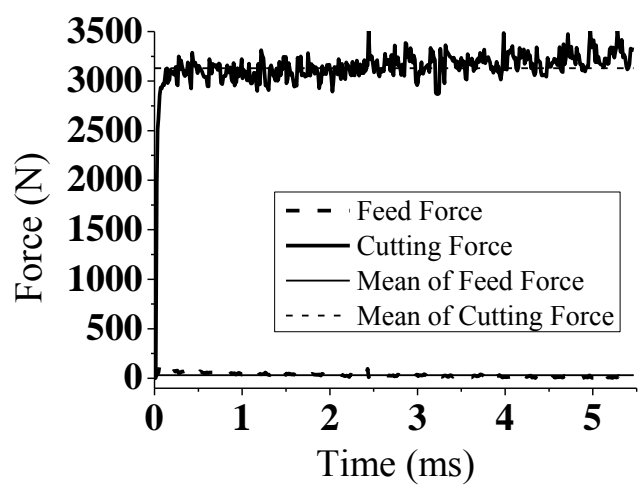

c)

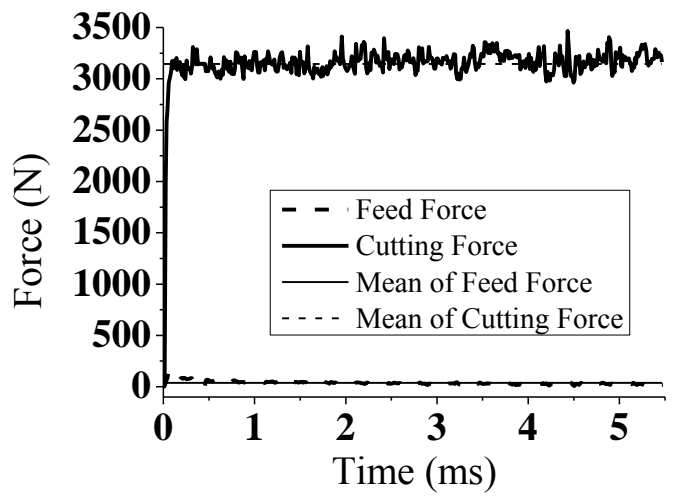

b)

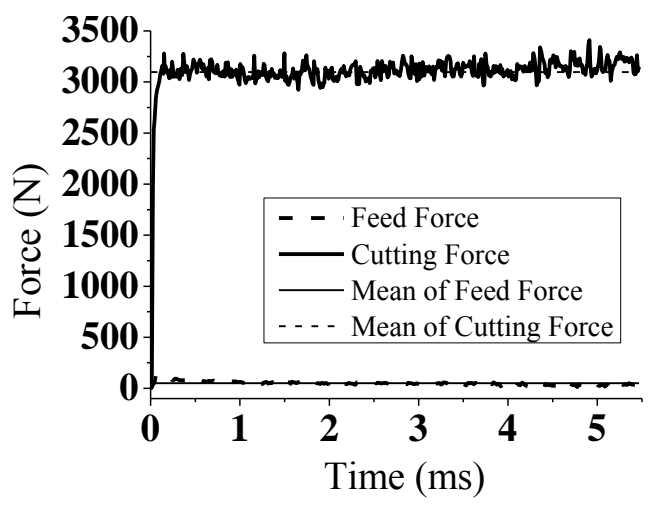

d)

Figure 6: Cutting force and Feed force's history: a) Traditional; b) Rectangular;

c) Trapezoidal;(d) Double-trapezoidal.

Fig.7 shows the field of temperature distribution on the tool rake face when the tool moves $8.2 \mathrm{~mm}$. The symmetrical tool-chip contact faces show symmetrical temperature distribution, as seen in Fig. 7 a, b and d. For the traditional tool, the maximum temperature arises at 50 per cent of the tool-chip contact area and reaches $461{ }^{\circ} \mathrm{C}$ because of the large tool-chip contact 
length. For the tool with a rectangular restricted contact shape, the temperature distribution is restricted to a small zone where the highest temperature is only $410{ }^{\circ} \mathrm{C}$. This value is about $11 \%$ lower than that in the tool-chip natural contact zone and it is about $6 \%$ by using the double-trapezoidal restricted contact tool. Asymmetric temperature distribution during the cutting process is seen in the case of the trapezoidal restricted tool but the highest temperature is close to that of traditional ones. The position of the highest temperature on the tool rake face should be paid attention to, for the concentration of heat may lead to serious tool wear and decrease the tool life.

The mean temperature on the rake face of the tool is an important parameter characterizing tool life. In this analysis, the mean temperature $T_{m}$ is obtained by using the following equation:

$$
T_{m}=\frac{\int T(x, z) d S}{S}
$$

where $T(x, z)$ is the temperature value in the point $(x, z)$ of the tool rake face, and $S$ the area of the tool-chip contact surface.

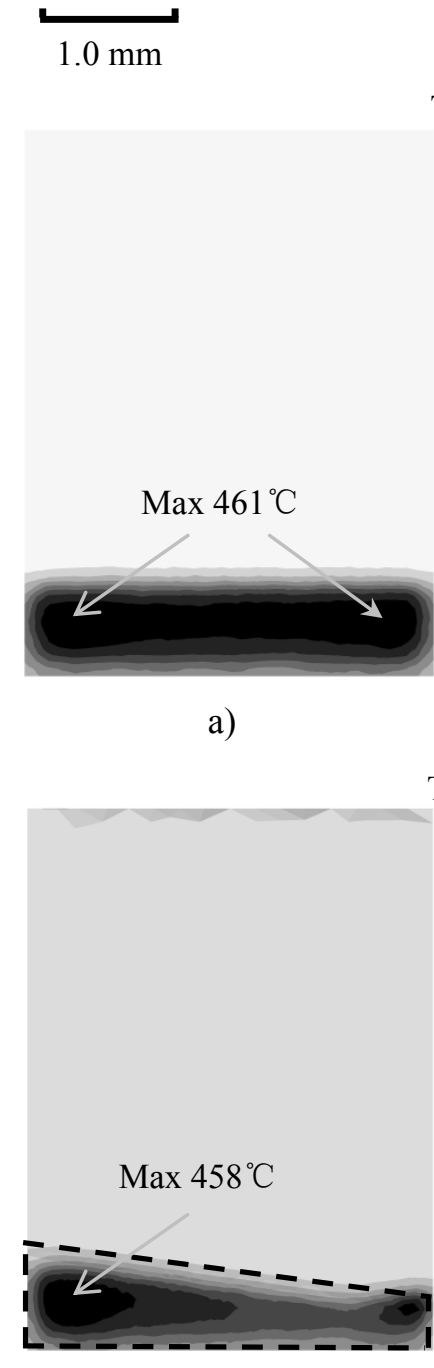

c)
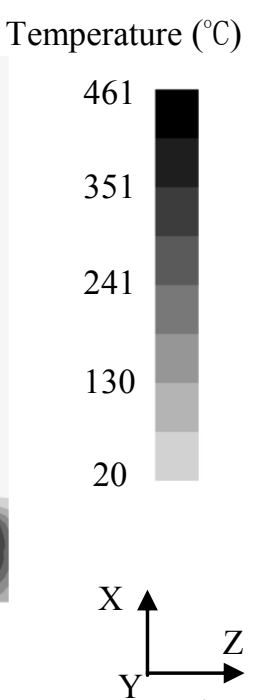

Temperature $\left({ }^{\circ} \mathrm{C}\right)$

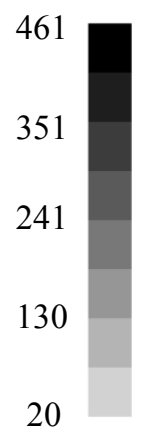

20

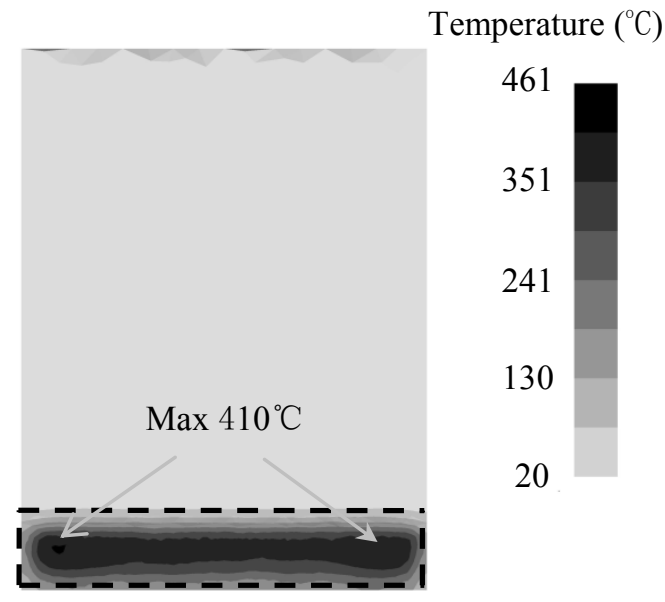

b)

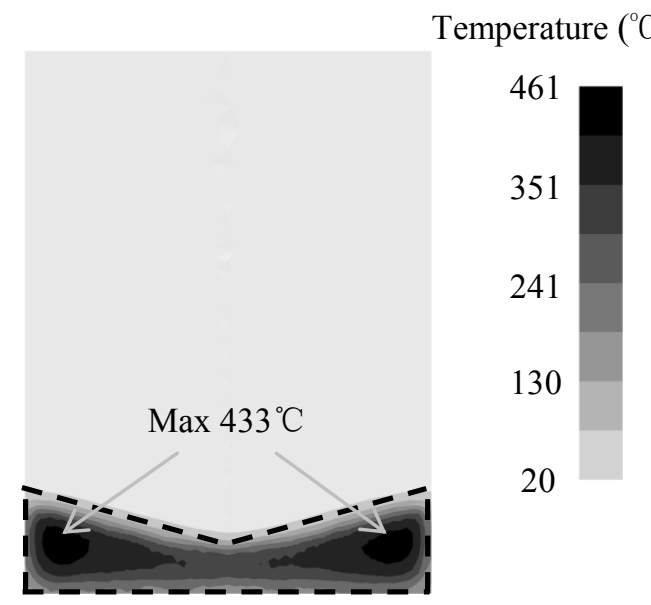

d)

Figure 7: Temperature distribution on rake face when the tool moves $8.2 \mathrm{~mm}$ : a) Traditional; b) Rectangular; c) Trapezoidal; d) Double-trapezoidal. 
Table IV shows that on the rake face of the traditional tool, the mean temperature is as high as $360.16{ }^{\circ} \mathrm{C}$ when the tool moves $8.2 \mathrm{~mm}$ forward. However, for the three kinds of RC tools, the mean temperatures are all lower by more than $12 \%$. This is tally to results from earlier studies [3-5]. The Reduction of the mean temperature means the decreasing of tool wear and prolonging of tool life.

Table IV: Mean temperature on the rake faces of tools when it moves $8.2 \mathrm{~mm}$.

\begin{tabular}{|c|c|c|c|c|}
\hline Tool type & Traditional & Rectangular & Trapezoidal & $\begin{array}{c}\text { Double- } \\
\text { trapezoidal }\end{array}$ \\
\hline$T_{m}\left({ }^{\circ} \mathrm{C}\right)$ & 360.16 & 313.50 & 302.70 & 312.25 \\
\hline $\begin{array}{c}\text { Relative } \\
\text { reduction* }\end{array}$ & 0 & $12.96 \%$ & $15.95 \%$ & $13.30 \%$ \\
\hline
\end{tabular}

* The mean temperature relative reduction is compared to the traditional tools.

\section{CONCLUSION}

In this analysis, an advanced finite element analysis code has been used to investigate the cutting process with three different $\mathrm{RC}$ tools. The following conclusions can be drawn from the work:

(1) Much easier chip breakage was found by using the unsymmetrical contact surface RC tools than the symmetrical ones in the simulation, as they rolled the chip to one side and deviated it from the cutting direction.

(2) Compared to the traditional tool, the mean cutting force is only $6 \sim 8 \%$ smaller by using restricted contact tools while the feed force is about 70 80\% less. In the three kinds of $\mathrm{RC}$ tools, the one with trapezoidal restricted contact surface shows the largest feed force reduction.

(3) The restricted contact geometry significantly influences the temperature distribution on the tool rake face. The mean temperature on the tool rake face is lower by more than $12 \%$ on using the restricted contact tool. The RC tool with trapezoidal restricted contact surface shows the lowest mean temperature.

\section{ACKNOWLEDGEMENTS}

This research was conducted under the support of the National Natural Science Foundation of China (50605022, 51075154), Fundamental Research Funds for the Central Universities (2012ZZ0057), Natural Science Foundation of Guangdong Province (06300160), and Zhujiang Science Technology New Stars Foundation (2011J2200066).

\section{REFERENCES}

[1] Klopstock, H. (1925). Recent investigation in turning and planning and a new form of cutting tool, Transactions of the ASME, Vol. 47, 345-377

[2] De Chiffre, L. (1982). Cutting tools with restricted contact, International Journal of Machine Tool Design and Research, Vol. 22, No. 4, 321-332, doi:10.1016/0020-7357(82)90009-9

[3] Sadik, M. I.; Lindström, B. (1995). The effect of restricted contact length on tool performance, Journal of Materials Processing Technology, Vol. 48, No. 1-4, 275-282, doi:10.1016/0924-0136(94)01659-O

[4] Huang, L. H.; Chen, J. C.; Chang, T. (1999). Effect of tool/chip contact length on orthogonal turning performance, Journal of Industrial Technology, Vol. 15, No. 2, 1-5 
[5] Arsecularatne, J. A. (2003). On prediction of tool life and tool deformation conditions in machining with restricted contact tools, International Journal of Machine Tools and Manufacture, Vol. 43, No. 7, 657-669, doi:10.1016/S0890-6955(03)00039-7

[6] Fang, N.; Jawahir, I. S.; Oxley, P. L. B. (2001). A universal slip-line model with non-unique solutions for machining with curled chip formation and a restricted contact tool, International Journal of Mechanical Sciences, Vol. 43, No. 2, 557-580, doi:10.1016/S0020-7403(99)00117-4

[7] Fang, N.; Jawahir, I. S. (2002). Analytical predictions and experimental validation of cutting force ratio, chip thickness, and chip back-flow angle in restricted contact machining using the universal slip-line model, International Journal of Machine Tools and Manufacture, Vol. 42, No. 6, 681-694, doi:10.1016/S0890-6955(02)00006-8

[8] Fang, N.; Jawahir, I. S. (2003). Analytical prediction of chip back-flow angle in machining with restricted contact grooved tools, ASME Journal of Manufacturing Science and Engineering, Vol. 125, No. 2, 210-219, doi:10.1115/1.1559159

[9] Wang, X.; Jawahir, I. S. (2003). Prediction of tool-chip interface friction and the chip-groove effects in machining with restricted contact grooved tools using the universal slip-line model, Key Engineering Materials, Vol. 233-236, 469-476, doi:10.4028/www.scientific.net/KEM.233236.469

[10] Arrazola, P. J.; Özel, T. (2010). Investigations on the effects of friction modeling in finite element simulation of machining, International Journal of Mechanical Sciences, Vol. 52, No. 1, 31-42, doi:10.1016/j.ijmecsci.2009.10.001

[11] Zhang, Y. C.; Mabrouki, T.; Nelias, D.; Gong, Y. D. (2011). Chip formation in orthogonal cutting considering interface limiting shear stress and damage evolution based on fracture energy approach, Finite Elements in Analysis and Design, Vol. 47, No. 7, 850-863, doi:10.1016/j.finel.2011.02.016

[12] Grzesik, W.; Bartoszuk, M.; Nieslony, P. (2005). Finite element modeling of temperature distribution in the cutting zone in turning processes with differently coated tools, Journal of Materials Processing Technology, Vol. 164-165, 1204-1211, doi:10.1016/j.jmatprotec.2005.02. $\underline{136}$

[13] Tamizharasan, T.; Senthil Kumar, N. (2012). Optimization of cutting insert geometry using DEFORM-3D: Numerical simulation and experimental validation, International Journal of Simulation Modelling, Vol. 11, No. 2, 65-76, doi:10.2507/IJSIMM11(2)1.200

[14] Puh, F.; Segota, T.; Jurkovic, Z. (2012). Optimization of hard turning process parameters with PCBN tool based on the Taguchi method, Technical Gazette, Vol. 19, No. 2, 415-419

[15] Nitu, E.; Iordache, M.; Marincei, L.; Charpentier, I.; Le Coz, G.; Ferron, G.; Ungureanu, I. (2011). FE-Modeling of cold rolling by In-Feed Method of circular grooves, Strojniski vestnikJournal of Mechanical Engineering, Vol. 57, No. 9, 667-673, doi:10.5545/sv-jme.2010.244

[16] Deng, W. J.; Xia, W.; Tang, Y. (2009). Finite element simulation for burr formation near the exit of orthogonal cutting, The International Journal of Advanced Manufacturing Technology, Vol. 43, No. 9-10, 1035-1045, doi:10.1007/s00170-008-1784-y

[17] Heisel U.; Krivoruchko D. V.; Zaloha W. A.; Storchak M.; Stehle T. (2009). FEM modelling as a modern method for the investigation of machining processes, ZWF Zeitschrift fur Wirtschaftlichen Fabrikbetrieb, Vol. 104, No. 7-8, 604-620

[18] Özel, T.; Zeren, E. (2004). Determination of work material flow stress and friction for FEA of machining using orthogonal cutting tests. Journal of Materials Processing Technology, Vol. 153-154, 1019-1025, doi:10.1016/i.jmatprotec.2004.04.162

[19] Bäker, M. (2005). Finite element investigation of the flow stress dependence of chip formation. Journal of Materials Processing Technology, Vol. 167, No. 1, 1-13, doi:10.1016/j.jmatprotec. 2004.09.076

[20] Jaspers, S. P. F. C.; Dautzenberg, J. H. (2002). Material behavior in conditions similar to metal cutting: flow stress in the primary shear zone, Journal of Materials Processing Technology, Vol. 122, No. 2-3, 322-330, doi:10.1016/S0924-0136(01)01228-6 
[21] Ackroyd, B.; Chandrasekar, S.; Compton, W. D. (2003). A model for the contact conditions at the chip-tool interface in machining, Journal of Tribology, Vol. 125, No. 3, 649-660, doi:10.1115/1.1537747

[22] Asthakov, V. P. (2006). Tribology of Metal Cutting, Vol. 52 (Tribology and Interface Engineering Series), 124-211, Elsevier Science, Amsterdam

[23] Iqbal, S. A.; Mativenga, P. T.; Sheikh, M. A. (2007). Characterization of machining of AISI 1045 steel over a wide range of cutting speeds. Part 1: investigation of contact phenomena, Journal of Engineering Manufacture, Vol. 221, No. 5, 909-916, doi:10.1243/09544054JEM796

[24] Bagci, E.; Ozcelik, B. (2006). Finite element and experimental investigation of temperature changes on a twist drill in sequential dry drilling, The International Journal of Advanced Manufacturing Technology, Vol. 28, No. 7-8, 680-687, doi:10.1007/s00170-004-2417-8

[25] Chang, C.-S. (2007). Prediction of the cutting temperatures of stainless steel with chamfered main cutting edge tools, Journal of Materials Processing Technology, Vol. 190, No. 1-3, 332-341, doi:10.1016/j.jmatprotec.2007.02.020

[26] Bartoszuk, M.; Grzesik, W. (2011). Numerical prediction of the interface temperature using updated finite difference approach, Advanced Materials Research, Vol. 223, 231-239, doi:10.4028/www.scientific.net/AMR.223.231

[27] Linke, B.; Duscha, M.; Vu, A. T.; Klocke, F. (2011). FEM-Based simulation of temperature in speed stroke grinding with 3D transient moving heat sources, Advanced Materials Research, Vol. 223, 733-742, doi:10.4028/www.scientific.net/AMR.223.733 